\title{
РАЗВИТИЕ ПОЗНАВАТЕЛЬНОЙ АКТИВНОСТИ БУДУЩИХ УЧИТЕЛЕЙ МУЗЫКИ НА ДИСЦИПЛИНЕ «ХОРОВОЙ КЛАСС И ПРАКТИКУМ РАБОТЫ С ХОРОМ»
}

\section{DEVELOPMENT OF COGNITIVE FUTURE MUSIC ACTIVITY TEACHERS IN THE DISCIPLINE "CHORAL CLASS AND PRACTICAL WORK WITH THE CHOIR"}

\section{K. Yesdauletova}

Summary: This article reveals the importance of the discipline "Choral class and practical work with the choir" for the development of cognitive activity of future music teachers.

Methodology of the work: The methodological and practical basis of conducting and choral training is presented within the framework of the refraction of various invariant pedagogical learning processes. We find confirmation of this position in V.I.'s article. Gastric "On the problem of modernization of conducting and choral training of a music teacher in the system of professional music and pedagogical education", where the main vectors of the process of modernization of specialized conducting and choral training are determined, due to significant changes, intensification of new approaches, directions and forms in pedagogical activity. The author deduced the quintessence of the creative refraction of the musical and pedagogical aspects of creation associated with the development of internal potential, cognitive motivation, self-realization of students in the process of empathic inspiration. He skillfully used the possibilities of choral art in the formation of feelings, emotions, taste, artistic interpretation in achieving his goals [1].

Conclusions: A creative approach will contribute to the development and self-improvement of specialists - future music teachers of cognitive and psychophysiological aspects of readiness for the process of personal selfdevelopment, to support interest in mastering artistic and performing activities, to identify potential personal and artistic-creative attitudes aimed at achieving high results in work, the ability to verbally and nonverbally express their own thoughts, while combining the synthesis of logical and emotional-imaginative thinking in substantiating their own creative musical interpretation, as well as activation of the sensitive and motivational-emotional sphere in personal development, etc.

Keywords: activity, cognition, cognitive activity, creativity, selfimprovement, empathy, sensitivity, activity, master classes.

\author{
Есдаулетова Камила Абдуалыевна \\ Казахская начиональная консерватория им. Курмангазы \\ dea84@mail.ru
}

Аннотация: Данная статья раскрывает значение дисциплины «Хоровой класс и практикум работы с хором» на развитие познавательной активности будущих учителей музыки.

Методология проведения работы: Методологическая и практическая основа дирижерско-хоровой подготовки представляется в рамках преломления различных инвариантных педагогических процессов обучения. Подтверждение данной позиции мы находим в статье В.И. Желудковой «К проблеме модернизации дирижерско-хоровой подготовки учителя музыки в системе профессионального музыкально-педагогического образования», где определены магистральные векторы процесса модернизации специализированной дирижерско-хоровой подготовки, обусловленные существенными изменениями, интенсификациями новых подходов, направлений и форм в педагогической деятельности. Автор вывел квинтэссенцию творческого преломления музыкально-педагогических аспектов созидания, связанное с развитием внутреннего потенциала, когнитивной мотивации, самореализации студентов в процессе эмпатийного вдохновения. Он умело использовал возможности хорового искусства в формировании чувств, эмоций, вкуса, художественной интерпретации в достижении поставленных целей [1].

Выводы: Творческий подход будет способствовать развитию и самосовершенствованию специалистов - будущих учителей музыки когнитивно-психофизиологических аспектов подготовленности к процессу личностного саморазвития, поддержать интерес к освоению художественно-исполнительской деятельности, выявлению потенциальных личностных и художественнотворческих установок, направленных на достижение высоких результатов в работе, умение вербально и невербально выражать собственную мысль, сочетая при этом синтез логического и эмоционально-образного мышления в обосновании собственной творческой музыкальной интерпретации, а также активизации сензитивной и мотивационно-эмоциональной сферы в личностном развитии и т.д.

Ключевые слова: активность, когнитивность, познавательная активность, творчество, самосовершенствование, эмпатия, сензитивность, деятельность, мастер-классы.

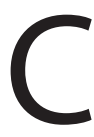

егодня обществу нужен конкурентоспособный специалист, который успешно владея основами профессионального мастерства, нацеленный на достижение высоких результатов в профессиональной деятельности, но и обладающий широким и глубоким мировоззрением, миропониманием и мировосприятием, готов осваивать и воспроизводить новые научные знания. В связи с чем, требования, предъявляемые к специалисту на современном этапе развития образования, предусматривают индивидуально творческий подход к его профессиональной подготовке, который обеспечивает овладение специальностью на личностном уровне. При этом можно не только выявлять наличие специальных способностей, но и формировать творче- 
скую индивидуальность, создавая для него такую образовательную среду, в которой бы он мог освоить навыки творческой деятельности, с учётом своеобразия своей индивидуальности построить личностную траекторию самосовершенствования.

Для молодого специалиста проблема самореализации и самоактуализации сегодня связана не только с уровнем развитого личностного музыкально-творческого потенциала, но и с умением выстоять на рынке труда, доказать свою профессиональную конкурентоспособность, оказаться полезным и значимым в творческо-созидательной, музыкально-педагогической деятельности. Всё вышесказанное свидетельствует о необходимости выработки новых подходов к процессу подготовки будущих учителей музыки, который способствует сформированности у будущего специалиста психофизиологической доминанты саморазвития, поддержать интерес к освоению исполнительской деятельностью, активизирует выявлению потенциальных личностных и художественно-творческих установок на достижение высоких результатов в работе, умение вербально и невербально выражать мысль, сочетать логическое и эмоционально-образное мышление в обосновании собственной творческой интерпретации, а также, сензитивную, эмоциональную сферу в личностном развитии и т.д. То есть, данное исследование, целенаправленно ориентировано на выработку, у будущих специалистов, навыков к овладению творческой дирижерско-хоровой деятельностью, умением использовать возможности когнитивной сферы художественных средств воздействия хоровой педагогики на формирование чувств, эмоций в процессе взаимодействий интегративных знаний в области художественного образования и, их влияния на развитие хорового образовательного процесса, в целом. Использование же специализированных (хороведческих) форм, методов, приемов, основанных на принципах методологии развития творческой личности, несомненно, благоприятствует формированию и раскрытию личностнозначимых, их творческих способностей.

Ведущие исследователи специалисты - А. Егоров, Н.М. Данилин, С.А. Казачков, К.А. Ольхов, Л.М. Абелян, В.Л. Живов, Т.Н. Овчинникова, В.И. Краснощеков и др., обращаясь к специфике взаимодействия учителя музыки - хормейстера с вокально-хоровым коллективом, рассматривали, ее, главным условием в достижении художественного результата.

Овладению технологией процесса формирования навыков самостоятельной творческой деятельностью были посвящены труды - дирижеров - Д.Л. Локшина, П.С. Чеснокова, В.Г. Соколова, К.Б. Птицы, Е.В. Николаевой, В.И. Краснощёкова, В.А. Чернушенко, Л.В. Шаминой, Г.П. Стуловой и др.
Научно понятийное содержание «познавательной активности учителя музыки» как интегративного качества личности, выражается в способности к целенаправленному, осознанному приобретению профессионально необходимых знаний, умений и навыков, в стремлении к более полному овладению способами будущей профессиональной деятельности, постоянному самосовершенствованию, в направленности на достижение высокого профессионализма. И для того, чтобы познавательная активность стала устойчивой потребностью, характером будущего учителя музыки, у него, наряду с собственными силами и умением овладевать знаниями, должен формироваться позитивный подход к самостоятельной познавательной деятельности. Познавательная активность или любознательность не ограничиваются выполнением будущим учителем музыки заданного задания без помощи другого. Он сознательно ставит перед собой цели, в соответствии с которыми мы даем ему следующее определение.

Профессиональная подготовка будущих учителей музыки -хормейстеров обусловлена многоаспективностью и сложностью выполнения многочисленных и многообразных поставленных задач, в разрешении неординарных, педагогических ситуаций, ориентированных на то, что выпускники, достигшие уровня творческой индивидуальности, имели практическую возможность более активно участвовать в построении новых духовных ценностей в сфере хоровой исполнительской практики, в развитии и становлении отечественной хоровой культуры и хоровой искусства.

Мы считаем, что развитие познавательной активности будущих учителей музыки - целенаправленный процесс развития устойчивых качеств личности будущего учителя музыки, отражающих потребность, желание и внутреннюю убежденность студента в необходимости творческого познания реальной действительности, способность формулирования познавательных задач и поиска их решения; результат, фиксирующий факт приобретения будущим учителем навыка творческого отношения к процессу учения, устойчивой потребности в познавательной деятельности; фактор изменения личностных качеств будущего учителя, среди которых: социальная ориентация, аксиологическая направленность личности, способность к рефлексии, к сотрудничеству, целеустремлённость, настойчивость, умение выдвигать познавательные задачи и самостоятельно их решать и др.

Необходимость данного исследования обусловлено тем, что в научной, музыкально-педагогической литературе изучению проблем подготовки дирижеров-хормейстеров, в целом, и в частности, овладению навыками творческой деятельности не уделяется достаточно внимания. 
Вопросы, связанные с музыкально-педагогической деятельностью, раскрывающие сущность и специфику формирования навыков освоения художественно-творческой деятельностью в хоровой деятельности, творческого характера взаимосвязи и взаимоотношения дирижера с исполнительским хоровым коллективом, дидактические особенности освоения своеобразной технологии специализированных (хороведческих) знаний.

В плане сказанного, особую актуальность представляет дисциплина "Хоровой класс и практическая работа с хором", который является основным профильным предметом специальных дисциплин дирижерско-хорового цикла, обеспечивающий целенаправленную профессиональную подготовку специалистов-хормейстеров. Основной целью предмета является развитие у студентов профессиональных навыков и умений пения в хоре, а также навыков управления хоровым коллективом на основе овладения методами работы с хором, дидактическими принципами и знаниями о психофизических процессах, происходящих в организме певца. Творческая личность студента формируется в хоровом классе через развитие его познавательной активности, которая выражается в различных аспектах его деятельности. С одной стороны, студент является членом хорового коллектива, учится и поет в хоре под руководством преподавателя (1-4 курс); с другой стороны, та же хоровая группа служит основой для приобретения студентом практических навыков и навыков управления хором в качестве дирижера.

Участие студентов в хоровом классе в качестве певцов: воспитывает и развивает профессиональные навыки будущего специалиста, который будет работать в детских вокально-хоровых коллективах; развививает певческие и слуховые навыки, включая точную интонацию в линейной мелодической вокализации и аккордногармоническую текстуру; формирует "вокальное ухо" - важный фактор в пении в единой вокальной манере, используя одни и те же принципы звукообразования, дыхания, тембровой красочности, дикции и т.д.; организует организует художественно-артистическую художественную волю, чтобы выявить и идентифицировать образно- творческие компоненты во время выполнения работы.

Работая с хором в качестве хормейстера, студент будущий учитель музыки приобретает навыки дирижера-исполнителя. В творческом общении с хором у него развиваются организаторские способности, исполнительская воля, умение устанавливать психологические и творческие контакты с каждым из участников хора и с хором в целом. В связи с тем, что предмет "Хоровое занятие и практикум работы с хором" не является лекционно-семинарским курсом, главное - занятия с хором его руководителя. Предмет "Хоровое занятие и практикум работы с хором" помогает углубленному всестороннему пониманию выбранной профессии. Знакомство с материалом курса обогащает интеллектуально, образно, эмоционально, художественно, привнося в музыкальную педагогику идейные основы и гармонию личностного развития

Целью преподавания дисциплины является

- воспитание эстетически развитого учителя музыки, подготовка студента к организации и осуществлению вокально-хоровой деятельности студентов в условиях регулярной и внеурочной работы;

- формировать и развивать у студентов профессиональные навыки пения в хоре, управления хоровым коллективом на основе овладения методами работы с хором.

Задачи изучения дисциплины:

- познакомить студентов с системой вокально-хоровой подготовки;

- познакомить студентов с лучшими образцами хорового творчества казахских и зарубежных композиторов, а также с народными песнями;

- получение музыкально-теоретического образования;

- воспитание ответственности руководителей. В соотвествии с задачами и выработаны соотвествующие требования к знаниям, навыкам, навыкам и компетенциям.

В результате изучения этой дисциплины студенты должны

- иметь представление: о культуре хорового исполнения; о настройке пения; о поющем дыхании; о поющем звуке; об основных типах хоровых стилей; знать: о высвобождении и активации артикуляционного аппарата, особенности дикции в процессе пения, о средствах музыкальной выразительности в пении; уметь самостоятельно работать над развитием голосового аппарата; воспроизведение художественного образа произведения в пении;

- быть способным к: овладеть певучим дыханием; расширение и укрепление индивидуального ассортимента; петь сольно и в ансамбле хоровой части всего хора; самостоятельно подготовить хоровое произведение для работы с хором;

- приобрести практические навыки: знание методов работы с хоровым коллективом; художественное исполнение различных хоровых произведений и школьных хоровых песен из репертуара стандартной музыкальной программы;быть компетентным, в вопросах особенностей развития взрослых, детских голосов и методов их защиты в разные возрастные периоды при выборе программы для хора, исходя из возможностей хора. 
В образовательном процессе профессиональное формирование хоровой культуры будущего учителя музыки в условиях высшего образования должно решаться на профессиональной основе и силами хорового класса как учебной дисциплины. Прежде всего, обобщение и практическое закрепление теоретических знаний и практических навыков, приобретенных студентами в ходе изучения ряда специальных дисциплин: хороведение, хоровая литература, дирижирование, постановка голоса, чтение хоровых партитур, хоровое переложение, гармония, сольфеджио, анализ музыкальных произведений и др. Аналогичную обобщающую функцию выполняют и другие учебные дисциплины, особенно дирижирование.

Вероятно, невозможно постоянно проводить занятия, не полагаясь на весь спектр профессиональных знаний, которыми обладает студент на данном этапе обучения. В то же время процесс закрепления знаний протекает достаточно эффективно. Однако даже занятия дирижирования не могут заменить обобщающего и практического значения работы в классе хора, который полностью построен на реальном (а не воображаемом) звучании хора. Недаром один из основоположников профессионального хорового образования А.Д. Кастальский подчеркнул роль хорового класса в воспитании будущих хормейстеров, сказав, что хоровые дирижеры "воспитываются самим хоровым звуком, точно так же, как многие симфонические и оперные дирижеры воспитывались оркестром, в котором они играли."

Еще одной проблемой, стоящей перед руководителем образовательного хорового коллектива, является вокальное образование его членов. Умение управлять своим голосом, практическое овладение техническими приемами пения необходимы будущему учителю музыки-хормейстеру не меньше, чем любые другие специальные теоретические знания и практические навыки. Ведь через некоторое время ему придется самому встать во главе хора и уже в качестве дирижера руководить его вокальным образованием.

"Дирижер должен, прежде всего, усвоить простую истину: нельзя учить других тому, чего не знаешь сам", сказал П.Г. Чесноков [2]. Поэтому будущий руководитель хора должен приобрести достаточные знания в области теории вокального пения, научиться в совершенстве овладевать певческим дыханием, четко понимать технологию и практически овладевать приемами правильного звукообразования, уметь пользоваться резонаторами, а также выработать набор вокальных и технических навыков, необходимых для исполнения произведений различных стилей и любой вокальной сложности. Сумма вокальных знаний и умений обеспечит высокий уровень вокально-хоровой культуры будущего учителя музыки, что, в свою очередь, станет залогом вокально-хоровой культуры возглавляемого им хорового коллектива.

Методически правильная, настойчивая и целенаправленная вокально - хоровая работа с учебным хором, как правило, позволяет, в конечном итоге, добиться высокохудожественных результатов. Звучание студенческого хора (обычно оснащенного голосами очень среднего качества) становится ярким и выразительным, значительно расширяются исполнительские возможности коллектива, обогащается его тембровая палитра [3].

Высокий уровень вокально - хоровой культуры учебного хора является необходимым условием развития еще одного важного профессионального качества будущего учителя музыки-хормейстера его вокального слуxa.

Вокальный слух - это тип музыкального слуха, характеризующийся особой чувствительностью к звучанию человеческого голоса во всех его тончайших тембровых, динамических, интонационных и других оттенках. Без вокального слуха невозможно отличить благородный "закрытый" звук от глухого, "заблокированного" звука; красивый, "круглый", чистый - от неестественного, нехудожественного и т.д. Только обладая вокальным слухом, дирижер может судить о степени художественного оформления звука, а следовательно, и о выразительности певческих качеств голоса [4].

Работа над вокальной стороной произведения тесно связана с воспитанием у студентов умения точно интонировать хоровые голоса партитуры, сохраняя при этом хорошее качество звучания.

На занятиях учебного хора приобретаются и совершенствуются такие специфические навыки хорового исполнения, как навыки хоровой структуры, хорового ансамбля и т.д., досконально изучается технология репетиционного процесса, воспитываются навыки исполнительской интерпретации.

Все эти профессиональные качества приобретаются будущими специалистами в процессе пения в хоровом учебном коллективе, поскольку " воспитание хорового дирижера должно осуществляться в постоянной связи с практикой пения в хоре."

Хоровой класс включает в себя концертную программу для выпускников. Защита государственного экзамена по специальности "Дирижирование" и "Работа с хором" является результатом работы студентов, в ходе которой закрепляются и совершенствуются знания и навыки, накопленные будущим учителем за время его участия в хоре в качестве певца, приобретаются навыки практической работы с хором при выступлении студентов в открытых концертах хорового класса в качестве 
дирижеров, а также решается ряд других организационных и творческих задач.

Сочетание успешных решений всех этих проблем на основе правильной организационной работы учебного хора, в конечном счете, обеспечивает правильное формирование хоровой культуры будущего учителя музыки. И здесь снова на первый план выходит проблема качества, уровня хоровой культуры образовательного хорового коллектива. "Точно так же, как пианиста нельзя научить играть на инструменте низкого качества, так и дирижера нельзя научить играть на плохом хоре. Образовательный хор ... она должна быть доведена до уровня высококвалифицированного художественного коллектива."

Очевидно, что даже самый талантливый студент-стажер не сможет воспитать и сформировать такую команду. Эта задача по силам только опытному, высококвалифицированному преподавателю.

Педагогика рассматривает воспитание личности и развитие специальных навыков и умений как единый неделимый процесс. Также хорошо известно, что формирование творческой личности никогда не бывает полным без влияния другой, не менее яркой творческой личности. В этой связи нельзя не отметить большое воспитательное значение личности педагога, всего профессионального облика руководителя хорового класса в сложном процессе формирования творческой личности каждого ученика, а в будущем-учителя музыки.

Важна и личность педагога-музыканта. Педагог-музыкант должен предстать перед аудиторией не просто эрудированным в области истории культуры, но способным мыслить, сравнивать, анализировать, а главноелюбящим, понимающим учеником, способным эмоционально воспринимать искусство. Он должен не только правильно исполнять музыкальный текст, но и передавать идейную суть произведения, его эмоциональную структуру, обладать широкой эрудицией в различных областях искусства. Поэтому всестороннее развитие музыкальных способностей, обучение основам хоровой культуры являются важнейшими задачами в процессе подготовки учителей музыки в общеобразовательных школах. Знакомство учителя с музыкальным материалом является образовательным процессом, так как расширяет представление об изучаемом материале.

Педагог знакомит с периодом создания музыкального произведения, основными этапами творческого пути автора, структурой и формой музыкального произведения, с преодолением исполнительскими приемами технического содержания произведения, сталкивается с поиском выразительных средств музыки в работе над художественным образом. Особенность этих знаний за- ключается в том, что они непосредственно связаны с отражением истории, современной жизни, социальных проблем, человеческих чувств и переживаний, формирующих знания и умения, личностные качества, обладающие воспитательным потенциалом. Обобщение теоретических знаний и умений, их применение в исполнительской интерпретации, умение их синтезировать развивают хоровую подготовку учителя музыки, ориентируют ценностные отношения к действительности, активно формируют духовный мир, художественный вкус, а следовательно, выполняют эстетическую функцию в образовательном процессе.

Для формирования хоровой культуры педагога-музыканта раскрывается художественно-воспитательный потенциал изучения и отбора репертуара хоровой музыки Казахстана с учетом опыта прошлого, в частности, достижений русской хоровой музыки.

Личность педагога, его талант, профессиональная эрудиция, опыт, а главное любовь и безраздельная преданность музыке, его профессия всегда должны быть примером, достойным подражания. Поэтому руководство учебным хором следует доверить одному из авторитетных преподавателей, который способен поднять студенческий хор на максимально профессиональный уровень, создать в коллективе по-настоящему творческую атмосферу. В этих условиях хоровой класс приобретает все основные качества, присущие исполнительским коллективам высшей квалификации, становится "творческой лабораторией", где закладываются основы профессионального мастерства будущих учителей музыки.

Одной из главных проблем учебного хорового коллектива является исполнительское воспитание будущих учителей музыки, что немыслимо без систематической концертной работы студенческого хора. Любой музыкант-исполнитель не может ограничивать свою профессиональную деятельность рамками репетиционной работы, так как в таком случае он неизбежно потеряет те необходимые художественные качества личности, которые воспитывает только сцена - общение с живой аудиторией, всю атмосферу концертного выступления.

Излишне говорить, что будущим учителям музыки необходимо овладеть исполнительскими навыками не меньше, чем скрипачу или пианисту. В период обучения эти навыки приобретаются, прежде всего, в процессе пения в учебном хоре под руководством опытного мастера-педагога. Следует подчеркнуть, что если формирование комплекса профессиональных вокально-технических навыков происходит в условиях репетиционного процесса, то только публичное концертное исполнение может служить стимулом для развития исполнительского таланта и артистизма. 
Образовательный и концертный репертуар хорового класса имеет большое значение для успешного исполнительского образования хора. Требования к учебному репертуару должны быть особенно высокими - ведь в процессе работы над репертуаром, помимо овладения необходимыми техническими и исполнительскими навыками, воспитывается художественный вкус будущих профессиональных музыкантов. Поэтому в репертуар хорового класса должны входить только лучшие образцы отечественной и зарубежной хоровой музыки. В хоровом классе необходимо постоянно изучать обширный хоровой репертуар, так как студенты знакомятся с лучшими образцами творчества крупнейших мастеров хоровой культуры разных эпох и творческих направлений, анализируя особенности репетиционной работы и исполнения хоровой музыки разных стилей.

В вопросах организации учебного хора также важна практика работы с хором. Практическая работа будущего хормейстера - проблема первостепенной важности, без решения которой невозможно обеспечить достаточно высокий уровень профессионального образования кадров. Очевидно, что решить проблему практической подготовки будущих хормейстеров только силами учебного хора невозможно, так как приобретение прочных навыков профессиональной работы с хором обеспечивается только постоянной работой с хоровым коллективом. Поэтому решение этой проблемы следует искать вне учебного хора.

Опыт ряда учебных заведений показывает, что при правильной постановке учебного процесса роль решающего фактора в практической подготовке приобретает хорошо организованная производственная практика студентов с различными самодеятельными хоровыми коллективами. Практические занятия с хором вне учебного заведения являются неотъемлемой частью педагогической работы с молодыми дирижерами. Она должна быть выполнена со всей строгостью и требовательностью. Роль самоподготовки студентов также очень важна. Студентам дается определенное количество вре- мени, чтобы подготовиться к последующим занятиям в хоровом классе. Эта потребность возникает из-за того, что студенты имеют возможность работать над конкретной задачей.

Пение хоровых голосов - важнейший момент в развитии хорового произведения. Изучение голосов достигается двумя способами: исполнением хоровых партий на фортепиано и повторением их голосом. Это так называемый механический способ запоминания мелодических линий хоровых партий. Такое усвоение материала является положительным, поскольку требует относительно небольшого количества времени.

Таким образом, вопросы организации работы учебного хора и практической подготовки будущих учителей музыки в условиях высшего музыкально-педагогического образования должны решаться комплексно. При этом приобретение навыков практической работы с хором осуществляется, прежде всего, в процессе систематической работы студента с хором.

рссмотрение познавательной активности будущего учителя музыки как педагогического явления исходит из его анализа как типовой формы познавательной активности по отношению к содержанию и особенностям преподавательской деятельности, области и предмета труда, условий их осуществления, образа мысли и субкультуры профессионального сооб-щества, меры соответствия личности заданным требованиям к профессии. Познавательная активность - такой вид учебной деятельности, при котором предполагается определенный уровень самостоятельности студентов во всех её структурных компонентах - от постановки проблемы до осуществления контроля, самоконтроля и коррекции, с переходом от выполнения простейших видов работы к более сложным, носящим поисковый характер. Для развития познавательной активности будущих учителей музыки необходимо использовать различные образовательные технологии, в том числе интерактивные формы обучения. Занятия проводятся в форме репетиций (практических занятий) и концертных выступлений.

\section{ЛИТЕРАТУРА}

1. Желудкова В.И. К проблеме модернизации дирижерско-хоровой подготовки учителя музыки в системе профессионального музыкально-педагогического образования (интегративный аспект) // Теория и практика общественного развития. 2013. - № 12.

2. Чесноков П.Г. Хор и управление им - М, 1961

3. Живов В.Л. Хоровое исполнительство: Теория. Методика. Практика. - М.: Гуманитарный Издательский Центр ВЛАДОС, 2003. - 272 с.

4. Казачков С.А. 0 дирижерско-хоровой педагогике. -В кн.: Музыкальное исполнительство. - М.: Музыка, 1970. - №6 - c.120-177.

5. Плужников К. Механика пения: принципы постановки голоса.- СПб.:Композитор-Санкт-Петербург, 2004

(с Есдаулетова Камила Абдуалыевна (dea84@mail.ru). 